\title{
Burning Effect of Sugarcane Residue After Cutting on the Diversity of Arthropods in Ratoon Sugarcane
}

\author{
Subiyakto $^{1 *}$, Sujak ${ }^{1}$, Dwi Adi Sunarto ${ }^{1}$ \\ ${ }^{1}$ Indonesian Sweeteners and Fiber Crops Research Institute, Malang 65152, Indonesia \\ *Corresponding author. Email: subiyaktosud@gmail.com
}

\begin{abstract}
Burning of sugarcane residue after cutting is often practiced by sugarcane farmers in ratoon sugarcane. Burning of crop residue facilitates soil management in addition to land sanitation needs to avoid pests and diseases in the next planting season. However, until now very limited information on effects of burning the sugarcane residues on the diversity of Arthropods in sugarcane plantations in the next planting season. Ecological sampling was conducted in Pakis Village, Malang Regency, East Java Province from September 2015 to December 2016. The study used an area of 1 ha, divided into two each with 0.5 ha for land with sugar cane residues not burned and 0.5 ha for land with sugarcane residues burned as farmers practice. Arthropods were surveyed using pitfall traps, yellow pan trap, net traps, and malaise traps. Speciemens are brought in to the laboratory for sorting and identification. Shannon-Weaver index, evenness index, and dominance index $(\lambda)$ were calculated to evaluate burning treatment on Arthropod community. The results showed that the burning of sugarcane residue after cutting is able to reduce diversity $\left(\mathrm{H}^{\prime}\right)$, decrease the evenness index $(\mathrm{E})$ and increase the dominance index $(\lambda)$ of arthropods. Burning of sugarcane residues after cutting will have detrimental effects on ecosystem instability.
\end{abstract}

Keywords: burning effect, sugarcane residue, diversity of arthropods, ecosystem instability, ratoon sugarcane

\section{INTRODUCTION}

The burning of sugarcane residues on planting land is contrary to the concept of sustainable agriculture. In many sugar-producing countries, sugarcane residues are not recommended to be burned but returned to the planting area. In Indonesia, that kind of burning is also not allowed according to Regulation No. 05/Permentan/Kb.410/1/2018 concerning Clearing or Processing of Plantation Land without Burning.

Returning sugarcane residues to planting areas at each harvest has proved to increase soil organic matter which is a tipping point for increasing sugarcane productivity [1]. Returning sugarcane residues to planting area has been proven to increase organic matter to $3.2 \%$ and increase $\mathrm{CO}_{2}$ emissions in the soil. In ratoon sugarcane, this condition will affect the initial growth of the ratoon sugarcane root system [2] and is a substrate of soil microorganisms also a positive thing for soil and land conservation [3].

Unfortunatelly, burning of sugarcane residues (trash, litter, shoots) after cutting is still recognized as a common practice by sugarcane farmers in ratoon sugarcane. It will facilitate land management in addition to land sanitation requirements to avoid pests and disease attacks in the next planting season. Another practice is burning sugarcane land after harvest to clean up trash or dried sugarcane leaves. So cutting down sugarcane will be much more manageable, faster and saves cutting power. In facts, the effect of burning sugarcane residues on soil conditions and the environment, especially arthropod diversity, has been carried out. Sajjad reported that burning sugarcane residues can cause a decline in natural enemy populations (ants and spiders) and an increase in pest populations (shoot borer and stem borer) in sugarcane in the following season [4]. Burning of biomass also damages soil fertility [5] and destroys biodiversity [6, 7] Reported that burning biomass after harvest would damage the physical, chemical, and biological properties of the soil and reduce $15 \%$ of carbon in the topsoil.

Because there is no information was found about the effect of burning sugarcane residues after cutting on arthropod diversity in sugar cane plantations in Indonesia. So, the study aims to determine the impact of burning sugarcane residues after cutting on arthropod diversity in ratoon sugarcane.

\subsection{Materials and Methods}

\subsubsection{Study site and study area}

The study was conducted from September 2015 to December 2016 in Pakis Subdistrict, Malang District, East 
Java Province. The research conducted in one location with 1 ha dry land that divided into two, 0.5 ha each. For treatment, land with sugarcane residues (12 tons/ha) and Clotalaria 10 tons/ha biomass is not burned (LTB) but returned to the land, while the other $0.5 \mathrm{ha}$, are treated with residues of sugar cane burned (LB) as farmers practice.

The variety used for this research is the second ratoon plant from the Bululawang variety. The replanting process was carried out on empty clumps using Bululawang variety a month after cutting. The distance between sugarcane rows (PKP) was $125 \mathrm{~cm}$. Plant maintenance adjusted to local location standards, with fertilizer doses, $400 \mathrm{~kg} \mathrm{~N}, \mathrm{P}$ and $\mathrm{K}$ compound fertilizers, and $600 \mathrm{~kg} \mathrm{~N}$ single fertilizer, which contains sulfur. A month after cutting, a total of $1 / 3$ single fertilizer $\mathrm{N}$ and all compound fertilizer were applied, and in 3 months after cutting $2 / 3$ single fertilizer $\mathrm{N}$ was applied.

\subsubsection{Arthopod sampling}

Arthropod observations were carried out randomly using pitfall traps, yellow pan traps, insect nets, and malaise traps. The collection is carried out randomly starting from 09.00 until 11.00. Observations were made monthly, from January to May.

Insect net with diameter of $60 \mathrm{~cm}$ and a length of $100 \mathrm{~cm}$ used to collect arthropods flying around the study sites. Sampling was conducted in four points with three repetitions, where at each observation point, 20 swings were carried out. Distance between observed points was about $1250 \mathrm{~m}^{2}$, with 20 swings carried out at each observation points.

Twelve pitfall traps were installed randomly with distance between traps was 10 meters. Traps are made from plastic cups, with $6 \mathrm{~cm}$ in diameter and $12 \mathrm{~cm}$ high, and the traps than installed by immersing them in the ground, where the surface is level with the soil. The trap filled with water added with $1 \%$ of detergent at $1 / 3$ of the cup height. On top of the trap, a plastic roof is provided to prevent water from entering when it rains. The observations are carried out every month, from January to May, and in each location, 4 points were observed using 3 repetitions. Pitfall traps are installed for a day (24 hours), and the collection results are taken and put into a plastic bag separately.

Yellow pan traps, made from a yellow plastic bowl, with $15 \mathrm{~cm}$ in diameter and $5 \mathrm{~cm}$ high, were set up near the pitfall traps $(1 \mathrm{~m})$ trap point. Traps installed on the ground and exposed the surroundings, then a third of the height of the bowl was filled with a detergent solution (1\%). Twelve yellow pan traps were installed for 24 hours, and arthropod were collecte and kept in a plastic bag separately. One malaise trap, modified from the original (Malaise and Rene 1937), were installed in each point and set up from 8:00 to 11:00.

\subsubsection{Sorting and identification}

Specimens were sorted by order and stored in wet collections, especially for soil insects such as Colembollas, ants, and spiders. They were maintained using a standard vial bottle filled with $80 \%$ alcohol. Specimens of Lepidoptera (moths) were treated as a dry collection, while the small order Hymenoptera (parasitoids) insects were kept in slides with the Hoyer medium [8].

\subsubsection{Data analysis}

Arthropod diversity associated with sugar cane was analyzed using a diversity index developed by ShanonWeaver [9] as follows:

$$
\begin{aligned}
& \mathrm{H}^{\prime}=-\sum[(\mathrm{ni} / \mathrm{n}) \operatorname{Ln}(\mathrm{ni} / \mathrm{n})] \\
& \mathrm{H}^{\prime}=\text { Diversity index } \\
& \mathrm{ni}=\text { The total number of individuals from one population } \\
& \mathrm{n}=\text { Total individuals from all population } \\
& \mathrm{Ln}=\text { Naturalist logarithm. }
\end{aligned}
$$

The Evenness index formula (El) from Pielou.

$$
\mathrm{El}=\frac{\sum \mathrm{H}^{\prime}}{\sum \mathrm{LnS}}
$$

$\mathrm{H}^{\prime}=$ Diversity index,

$\mathrm{S}=$ All types

$\mathrm{Ln}=$ Logarithmic numbers

Species Richness (R) are the number of species in a population

Species Richness (R) from Margalef [10].

$$
\mathrm{R}=\frac{S-1}{\operatorname{Ln} S}
$$

$\mathrm{S}=$ The total number of species

$\mathrm{N}=$ The total number of population

Dominance index $(\lambda)$ from Samson [11].

$$
\lambda=\sum \frac{N i(n i-1)}{n(n-1)}
$$

$\mathrm{ni}=$ is the total number of individuals of one population, $\mathrm{N}=$ total individuals of all population.

\subsection{Our Contribution}

This paper presents the negative impact of sugarcane residues burning after cutting on arthropod diversity in ratoon sugarcane. To facilitate land management, most farmers burn sugarcane residues. Burning sugarcane residues is not recommended by the government. Apart from causing smoke pollution, burning of sugarcane residue causes a reduction in arthropod diversity and causes ecosystem instability. 


\subsection{Paper Structure}

This paper organized as follows. Part 1 is an introduction that leads to research activities, consisting of arthropod sampling, sorting, identification, and data analysis. Part 2 background, consists of soil arthropods diversity, the total number of species, evenness index. The discussion focused on arthropods diversity of burned (LB) and unburned land (LTB) plant residues. Finally, in section 6 , the form of conclusions and suggestions for the future.

\section{RESULTS AND DISCUSSION}

In total, this research has successfully collected 8,156 individual of arthropod belonging to eight orders including Collembola, Hymenoptera, Araneae, Diptera, Coleoptera, Lepidoptera, Hemiptera, and Orthoptera, and other unidentified arthropods. In general, abundance of arthopod with all sampling method in unburned land was found to be higher than in burned land (Table 1). This can be seen from number of individuals collected using pitfall traps on unburned land (LTB) was 2,214, while on burned land (LB) was 1,463 . The similar result was also recorded with yellow pan traps, net traps, and malaise traps.

Collembola. From pitfall traps, abundance of Collembola was found to be higher in LTB treatment than in LB with total number of individuals was 978 and 672 respectivelly. Similar result was also recorded for yellow pan traps with abundance was higher in LTB than in LB. However, no individual of Collembola were collected from direct collection using insect nets and malaise traps. Since those two kinds of collection methods are more suitable for flying insects rather than Collembolla which live on the surface of the soil.

Hymenoptera. On observations using various traps consistently, the LTB treatment obtained a quantitatively higher amount of catch compared to LB. Observations using pitfall traps in the LTB treatment showed the number of Hymenoptera caught was 729, while in LB treatment was 415. The order of Hymenoptera dominated by ant species. Hymenoptera observation using yellow pan traps in the LTB treatment obtained 833 catches while in LB 206. The same tendency occurred in net traps and malaise traps observations. Aranaea. Aranaea observations using Pitfall traps and other trapping tools appear to be inconsistent. In the LTB treatment Pitfall traps observation, the number of Aranaea caught was lower (34) than LB (58). However, from yellow pan traps and net trap, abundance was recorded higher in the LTB treatment. The Aranaea Order was dominated by spider types.

Diptera. Diptera caught are dominated by flies and mosquitoes' types. The results consistently show that the number of Diptera collected in LTB treatment was higher than that of the LB treatment. Similar results also appear in the same method using another tool such as yellow pan trap.
Coleoptera. In the LTB treatment, the observation using pitfall traps showed that Paederus sp dominated Coleoptera community with number of indivual was 58 , in contrast in the LB treatment was 34. Similar trend was also recorded from other methods such as, yellow pan trap.

Lepidoptera. For Lepidoptera order, both in LTB and LB using all applied collection method, number of indivual collected was found to be very small ranging from 1 to 4 individuals.

Hemiptera. Hemiptera caught are dominated by various types of planthopper. In the LTB treatment, the observation by using the Pitfall trap had 288 catches, while for LB treatment 146. For the Hemiptera order, the catch amount of each method using various traps did not give consistent results.

Orthoptera. Orthoptera captured was dominated by various types of crickets. In the LTB treatment, the number of individuals were 28, in contrast in the LB treatment was 44 . The number of Orthoptera collected from same treatment and all different collection methods were inconsistent.

Unidentified order. The unidentified order caused by the specimen being caught broken, making identification difficult. The number of unidentified Arthropods is between 4-37 species.

The total number of Arthropods observations on plants ages, 3, 4, 5, 6, and 7 months presented in Table 2. Arthropoda catches, at the age of plants from 3 to 7 months from observations using various trap devices show that the number of Arthropods taken in the LTB treatment consistently is higher than the LB treatment.

\subsection{Diversity of Soil Arthropods}

The Shanon-Wiever diversity index results calculation $\left(H^{\prime}\right)$, the number of individual types (No), evenness index (E), species richness index $(\mathrm{R})$, and dominance index $(\lambda)$ of species collected from pitfall trap method and yellow pan traps are presented in Table 3. From pitfall traps, $H^{\prime}$ index for LTB and LB is 1.28 and 1.23 respectivelly. While $\mathrm{H}^{\prime}$ index from yellow pan traps for LTB and LB is 1.37 and 1.26 respectivelly. According to Shanon-Wiever index value for $\mathrm{H}^{\prime}$ $\geq 1.0$ is classified as moderate diversity which indicates that the number of species and population varies, and a relatively stable ecosystem.

\subsection{The Total Number of Species}

Based on Table 3, the total number of species (No) in LTB treatment using the pitfall traps observation method was found to be 4 points higher than LB with 18.2 for LTB and 14.2 for LB treatment. LTB treatment using the yellow pan traps observation method is 0.6 higher than LB treatment. 
Therefore, unburned land (LTB) treatment can maintain higher number of soil arthropods species.

\subsection{Evenness Index}

Evenness index used to measure the level of evenness or abundance of species distributed among species in an environment. Kreb reported that the size of the population evenness is in line with the evenness index, a small evenness index means that the total number of species in a population is not the same, and there is a tendency for one species to dominate [12]. Also vice versa, the higher the evenness index, means that the higher the total number of species in a population and there is no tendency for one species to dominate.

Table 1 Total Arthropods collected from various traps in unburned land (LTB) and burned land (LB) treatment

\begin{tabular}{|l|r|r|r|r|r|r|r|r|}
\hline \multirow{2}{*}{$\begin{array}{c}\text { Arthhropoda } \\
\text { Order }\end{array}$} & \multicolumn{2}{|c|}{ Pitfall traps } & \multicolumn{2}{c|}{ Yellow pan traps } & \multicolumn{2}{c|}{ Net traps } & \multicolumn{2}{c|}{ Malaise traps } \\
\cline { 2 - 9 } & $\begin{array}{c}\text { Unburned } \\
\text { land } \\
\text { (LTB) }\end{array}$ & $\begin{array}{c}\text { Burned } \\
\text { land } \\
\text { (LB) }\end{array}$ & $\begin{array}{c}\text { Unburned } \\
\text { land } \\
\text { (LTB) }\end{array}$ & $\begin{array}{c}\text { Burned } \\
\text { land } \\
\text { (LB) }\end{array}$ & $\begin{array}{c}\text { Unburned } \\
\text { land } \\
\text { (LTB) }\end{array}$ & $\begin{array}{c}\text { Burned } \\
\text { land } \\
\text { (LB) }\end{array}$ & $\begin{array}{c}\text { Unburned } \\
\text { land } \\
\text { (LTB) }\end{array}$ & $\begin{array}{c}\text { Burned } \\
\text { land } \\
\text { (LB) }\end{array}$ \\
\hline Collembola & 978 & 672 & 760 & 503 & - & - & - & - \\
\hline Hymenoptera & 729 & 415 & 833 & 206 & 234 & 176 & 39 & 19 \\
\hline Araneae & 125 & 148 & 98 & 28 & 62 & 43 & - & - \\
\hline Diptera & 7 & 4 & 35 & 24 & 153 & 106 & 29 & 20 \\
\hline Coleoptera & 58 & 34 & 49 & 51 & 76 & 74 & 0 & 3 \\
\hline Lepidoptera & 1 & 0 & 4 & 4 & - & - & 1 & - \\
\hline Hemiptera & 288 & 146 & 48 & 80 & 201 & 96 & 2 & 2 \\
\hline Orthoptera & 28 & 44 & 201 & 50 & 103 & 3 & - & - \\
\hline Unidentified & 37 & 35 & 20 & 5 & 10 & 7 & 5 & 4 \\
\hline Total & 2214 & 1463 & 2048 & 951 & 839 & 512 & 81 & 48 \\
\hline
\end{tabular}

Table 2 Total Arthropods caught in various traps in the treatment of unburned land (LTB) and burned land (LB) at plant ages 3, 4, 5, 6 and 7 months

\begin{tabular}{|c|c|c|r|r|r|r|}
\hline \multirow{2}{*}{$\begin{array}{c}\text { Age of } \\
\text { observation } \\
(\text { month) }\end{array}$} & \multicolumn{2}{|c|}{ Pitfall traps } & \multicolumn{2}{c|}{ Yellow pan traps } & \multicolumn{2}{c|}{ Net traps } \\
\cline { 2 - 7 } & $\begin{array}{c}\text { Unburned } \\
\text { land (LTB) }\end{array}$ & $\begin{array}{c}\text { Burned land } \\
(\text { LB) }\end{array}$ & $\begin{array}{c}\text { Unburned } \\
\text { land (LTB) }\end{array}$ & $\begin{array}{c}\text { Burned land } \\
(\text { LB) }\end{array}$ & $\begin{array}{c}\text { Unburned } \\
\text { land (LTB) }\end{array}$ & $\begin{array}{c}\text { Burned land } \\
\text { (LB) }\end{array}$ \\
\hline 3 & 595 & 290 & 719 & 137 & 151 & 79 \\
\hline 4 & 400 & 267 & 370 & 215 & 72 & 35 \\
\hline 5 & 382 & 350 & 367 & 153 & 193 & 136 \\
\hline 6 & 527 & 296 & 404 & 278 & 128 & 101 \\
\hline 7 & 310 & 260 & 188 & 168 & 295 & 161 \\
\hline Total & 2214 & 1463 & 2048 & 951 & 839 & 512 \\
\hline
\end{tabular}

Table 3 Diversity index and abundance of soil arthropods resulting from pitfall trap and yellow pan trap installation in sugar cane land using unburned land (LTB) and burned land (LB) treatment in Pakis, Malang Regency 2016

\begin{tabular}{|l|c|c|c|c|c|c|c|c|c|c|}
\hline \multirow{2}{*}{$\begin{array}{c}\text { Observation } \\
\text { method }\end{array}$} & \multicolumn{2}{|c|}{ H' } & \multicolumn{2}{c|}{ No } & \multicolumn{2}{c|}{ E } & \multicolumn{3}{c|}{ R } & \multicolumn{2}{c|}{$\boldsymbol{\lambda}$} \\
\cline { 2 - 12 } & LTB & LB & LTB & LB & LTB & LB & LTB & LB & LTB & LB \\
\hline Pitfall trap & 1,28 & 1,23 & 18,2 & 14,2 & 0,48 & 0,47 & 2,85 & 2,38 & 0,35 & 0,40 \\
\hline Yellow pan traps & 1,37 & 1,26 & 17,4 & 16,8 & 0,47 & 0,44 & 3,21 & 3,15 & 0,39 & 0,46 \\
\hline
\end{tabular}

Note $H^{\prime}$ : diversity index; No: the total number of species; E: evenness index; R: species richness index; $\lambda$ : dominance index 
Evenness index (E) of LTB and LB treatment both using the pitfall trap and yellow pan trap observation method, ranges from 0.44 to 0.48. According to Shanon-Wiever Evenness index values close to 0.5 indicate a moderate evenness index, which means smaller population dominance, distribution of the number of species in a population is the same, and there is no tendency for one species to dominate.Therefore, Arthropods species in this research is evenly distributed, especially in LTB treatment. Species Richness (R) in LTB (2.85) treatment using the pitfall traps observation method was higher than LB treatment (2.38). Meanwhile, in LTB treatment using the yellow pan trap observation method was 3.21 compared to LB 3.15. The high value of $(\mathrm{R})$ on the land added by biomass (LTB treatment) is caused by the cumulative of all arthropods species (S) in LTB treatment is higher than the LB treatment.

Dominance index $(\lambda)$ shows the magnitude of species role in its relation with its population or environment as a whole. Both lands treated using LTB or LB have a dominance index $(\lambda)$ ranging from 0.35 to 0.46 . The dominance index value ranges from $0-1$ and the smaller the dominance index, the smaller the population dominance. It means species are more evenly distributed and there is no tendency for one species to dominate. Vice versa, the higher the dominance index value, the higher the tendency for one species to dominate [12].

From the pest control aspect, LTB treatment can maintain higher diversity $\left(\mathrm{H}^{\prime}\right)$, evenness index $(\mathrm{E})$, and decrease the dominance index $(\lambda)$ of soil arthropods. Whereas LB treatment will reduce diversity $\left(\mathrm{H}^{\prime}\right)$, decrease the evenness index (E) and increase the dominance index $(\lambda)$ of soil arthropods. Thus, burning of sugarcane residue will have negative effects on ecosystem stability. Previous research revealed that burning of sugarcane residue is able to decrease natural enemy populations, and trigger an increase of pest populations in sugarcane plantation in the following season [4].

Returning sugarcane residues to land in addition to increasing soil organic matter, returning biomass can in fact increase arthropod diversity [13] and improve soil microbial performance [14] or generally increase biodiversity. In the field of sugarcane plant pest and disease control, increasing biodiversity will provide various benefits, namely small-sized soil insects/collembola as hosts of predatory insects [15]. High biodiversity can be used as an indicator of the stability of an ecosystem [16].

A stable ecosystem allows various arthropods such as natural enemies (parasitoids and predators), pollinators, neutral insects, and microbial decomposers to play an optimal role. Besides returning biomass to the land can also maintain soil moisture, soil protection against erosion and leaching of nutrients [17], controlling weeds [10] and especially in increasing organic matter and nitrogen by soil microorganisms [18].

\section{CONCLUSION}

Burning sugarcane residues after harvest has reduced abundance of Arthropods based on observations using the pitfall traps, yellow traps, net traps, and malaise traps methods. It affects diversity ( $\left.H^{\prime}\right)$, the evenness index $(E)$, and increase the arthropod dominance index $(\lambda)$. From pest control point of view, burning of sugarcane residues has detrimental effects on ecosystem instability.

\section{ACKNOWLEDGMENT}

The author would like to thank Indonesian Agency for Agricultural Research and Development for funding support for this research through the 2015 State Budget.

\section{REFERENCES}

[1] F.C. Dalchiavon, M.P. Carvalho, R. Montanari, M. Andreotti, E.A.D. Bem, Sugarcane trash management assessed by the interaction of yield with soil properties, Revista Brasileira de Ciência do Solo, Sociedade Brasileira de Ciência do Solo Viçosa, Brazil, 37(6) (2013), pp. 1709-1719

[2] F. Muñoz-Arboleda, R. Quintero-Duran, Trash management after green cane harvesting and its effect on productivity and soil respiration, Int. Sugar J. 113 (1355) (2011) 804-808

[3] S.M. Prasanna, P.S. Pattar, Successful ratoon management in sugarcane, RRJAAS, 3(4) (2014) 3947

[4] A.F. Sajjad, A.H. Ahmad, Makhdoom, A. Imran, Does trash burning harm arthropods biodiversity in sugarcane, Int. J. Agric. Biol. 14 (2012) 1021-1023

[5] R.A. Souza, T.S. Telles, W. Machado, M. Hungria, and J.T. Filho, Effects of sugarcane harvesting with burning on the chemical and microbiological properties of the soil, Agric Ecosyst Environ. 155 (2012): 1-6

[6] J.A. Ludwig, J.F. Reynold, Statistical Ecology, Wiley Interscience Publication, John Wiley and Sons, New York, 1998

[7] J. Srikanth, S. Easwaramoorthy, N.K. Kurup, and G. Santhalaksmi, Spider abundance in sugarcane: impact of cultural practices, irrigation and postharvest trash burning, Biologic. Agric. Hortic. 14 (1997) 343-356 
[8] R.C. Henderson, Technique for positional slidemounting of Acari, Systematic and Applied Acarology, 2001, pp. 7

[9] W. Sornpoon, S. Bonnet, S. Garivait, Effect of open burning on soil carbon stock in sugarcane plantation in Thailand. Int. J. Environ. Chem. Ecologic. Geologic. Geophysic. Engineer. 7(11) (2013) 775779

[10] D.G. Patriquin, Nitrogen fixation in sugarcane litter, Biol. Agric. Hortic. 1 (1982) 39-64

[11] T.R.E. Southwood, Ecological methods, with particular reference to the study of insect populations, The English Language Book Society and ChopanHall, London, 1978, 524p

[12] C.J. Kreb, Ecology: the experimental analysis of distribution and abundance, Published by Harper and Row, 1972, 694p

[13] B.M. Doube, O. Schmidt, Can the abudance or activity of soil microfauna be used to indicated the biological health of soils, Biological indicators of Soil Health, Edited by C.E. Pakhrust, B.M. Doube, V.V.S.S.R Gupta, CAB International, 1998, pp. 265 295

[14] G.P. Sparling, Soil microba biomass, activity and nutrient cycling as indicators of soil health, biological indicators of soil health, Edited by C.E. Pakhrust, B.M. Doube, V.V.S.R. Gupta, CAB International, 1998, pp. $97-120$

[15] V.P.T Selvi, M. Dayana, Biodiversity of insect in sugarcane field at a Vadipati, Tamil Nadu, India, Int. Res. J. Environ. Sci. 4 (4) (2015) 74-79

[16] T.P. Inayat, SA. Rana, H.A Khan, K. Rehman, Diversity of insect fauna in cropland of district Faisalabad, J. Agri. Sci. 47 (3) (2010) 245-250

[17] K.H. Tan, Soil sampling, preparation, and analysis. Marcell Decker, INC, 1995, ISBN: 0-8247-9675-6

[18] P. Shah, Weeds associated with tillage, mulching and Nitrogenin wheat and their effecton yield: a review. IJGAES. 1 (1) (2013) 20-25 